\title{
Optical Research: A Curated Visual Music Collection
}

\author{
Jonathan Weinel \\ Glyndŵr University \\ Plas Coch Campus, Mold Road \\ Wrexham, LL112AW, North Wales, UK \\ j.weinel@glyndwr.ac.uk
}

\section{INTRODUCTION}

Optical Research is a curated collection of visual music by a group of 12 international artists, which has recently been presented as a DVD, a gallery installation, and will be presented at the British Computer Society Electronic Visualisation and the Arts: EVA London 2015.

'Visual music' describes a form of filmmaking in which animated visual images of a typically abstract nature are arranged into music-like structures (Brougher \& Mattis, 2005). While the origins of visual music lie in the early colour organ inventions or the paintings of artists such as Kandinsky, 'visual music' as a form of experimental film-making in the mid $20^{\text {th }}$ Century was pioneered by artists such as John Whitney, Oskar Fischinger, Jordan Belson and others. John Whitney sought to provide a form of 'visual harmony' that mirrored that provided within music (Whitney, 1981). Jordan Belson's work explores similar approaches, but was particularly concerned with the use of abstract visuals in order to reflect music of the 'inner eye', which related aspects of internal experience. Perhaps the most well known example of visual music however is Walt Disney's Fantasia (1940), which uses animated cartoon narratives to reflect well-known orchestral pieces of music.

While the pioneering early work of these artists utilised various hand-produced animation techniques, John Whitney and Larry Cuba's subsequent experiments with early computer graphics would prefigure much of the digitally based work in this area during the 1980s, 1990s and beyond. As I discuss elsewhere, computer music visualisations, light-synths, VJ performances, and 3D music videos are among those forms of computer-based music-related visual culture to emerge subsequently (Weinel et al., 2014). This culture continues today, with the most recent iterations including interactive work such as music video games, and the use of projection mapping in live audio-visual performances.

Optical Research then, is a collection of video artworks that documents a cross-section of important recent works by performers working in areas broadly associated with visual music and related areas such as VJ, electroacoustic audio visual, experimental film, video music and audiovisualisation. It is also conceived with respect to a 'cyberdelic' view of visual music: a concept we shall now briefly discuss.

\section{CYBERDELIC CULTURE}

Perhaps due to the proximity of visual music artists to the Californian counter culture movements of the 1960s, visual music acquired an association with psychedelic culture. This arises from the use of abstraction in the work of artists such as Jordan Belson, which can be seen as describing internal visual images such as those that might be experienced during an LSD experience (Wees, 1992). The synesthetic priorities of the work also readily afford an association with psychedelic drugs; the use of which promotes synesthetic experiences. Perhaps unsurprisingly then, there are also clear parallels between visual music and the liquid light shows of 1960 s rock concerts, which also use abstract imagery as a compliment to music.

Through the 1980s and 1990s these associations continued through the relationship between rave culture and computer technology, which gave rise to VJ culture (as seen on the Studio !K7 X-Mix series for example). VJ culture is just one example of a nexus between psychedelic culture and computer technology, which also extended into the virtual reality domain and was significantly influenced by the literary works of cyberpunk authors such as William Gibson. 
This nexus of psychedelic culture and immersive computer technologies has been referred to as 'cyberdelic' (a portmanteau of cyberspace and psychedelic) and was notably articulated in Timothy Leary's Chaos and Cyberculture (1994), and in the work of Terrance McKenna. This 'cyberdelic' outlook is the conceptual view of visual music that informs the assembly of Optical Research: I have selected works that broadly relate to this theme. The works can be seen to explore this concept through direct reference to altered states of consciousness or shamanic themes; digital surrealism, psychedelic abstraction or hypnotic visual effects; or through glitch aesthetics, hardware hacking and 3D fractals which reflect the digital consciousness and discourses of the current generation of visual music artists.

\section{OPTICAL RESEARCH}

Optical Research contains 12 pieces by a mixture of new and established artists on the international visual music scene. The pieces have already been widely screened at events such as Seeing Sound (Bath), Edinburgh Film Festival, Sweet Thunder Festival (San Francisco), Punta y Raya (Reykjavik), DotMov festival (Tokyo), the International Computer Music Conference (Athens) and others.

1. Ryo Ikeshiro - Construction in Kneading

2. Josh Simmons - BitPushIntersection

3. Ocusonic-Chasing Waves

4. Benjamin Rowley - Optical Sound Film No.2

5. Jon Weinel - Mezcal Animations

6. Maxime Corbeil-Perron - Ghostly

7. Diego Garro - Patah

8. Mark Pilkington \& Richard Scott - Surface

9. Scott Kiernan \& Victoria Keddie - 33

10. Diego Capoccitti - Epithymetikòn

11. VJ Chaotic \& Vibrasphere - Forever Imaginary

12. Brummbaer - Where in the Universe is Timothy Leary?

The collection includes pieces that encompass a range of styles and artistic approaches; from audiovisualisations of data, glitch and trips through 3D fractal universes, to hacked analogue video equipment and pieces produced using paint and $8 \mathrm{~mm}$ film. Among those works included is a tribute to Timothy Leary by the renowned digital artist Brummbaer, whose work has previously been featured in Timothy Leary's Chaos and Cyberculture (1994) and the movie adaptation of William Gibson's Johnny Mnemonic (1995).

Optical Research is a feast for the eyes and ears that explores visual music with a distinctly dark, psychedelic and cybernetic edge. At once embracing the aesthetics of the past in visual music, while forging daring new trajectories, the presentation is essential viewing for audiences of sonic art, expanded cinema, cyberpunk culture and psychedelia.

At the time of writing, the collection is available to purchase as a limited edition DVD (Figure 1) from www.hardcorejewellery.co.uk and is currently being exhibited at the Axis Arts Centre in Crewe (9-20 March 2015).

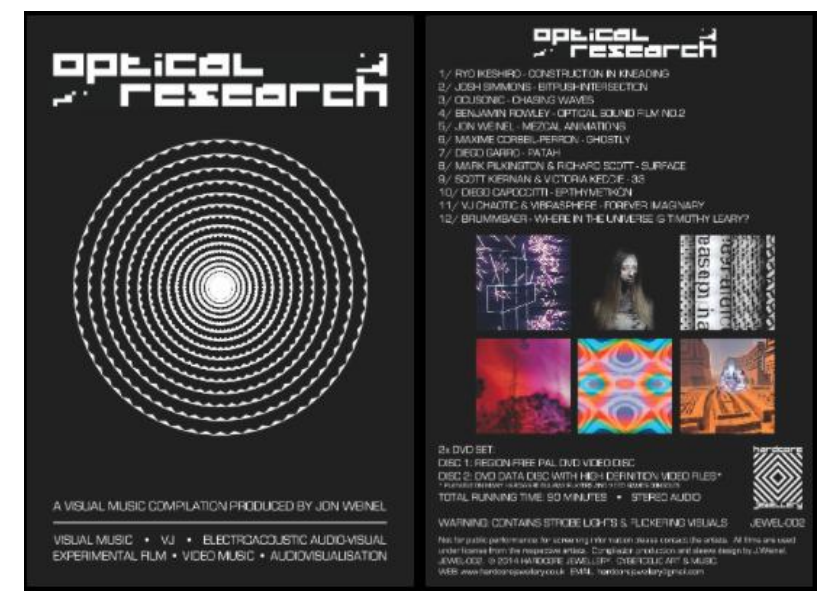

Figure 1: Optical Research DVD artwork

\section{ACKNOWLEDGEMENTS}

The production of Optical Research owes the most sincere debt to the artists involved, who kindly agreed for their work to be included in this project.

\section{REFERENCES}

Brougher, K. \& Mattis, O. (2005) Visual Music: Synesthesia in Art and Music since 1900. Thames \& Hudson.

Leary, T. (1994) Chaos and Cyberculture. Ronin Publishing.

Wees, W. C. (1992) Making Films for the Inner Eye: Jordan Belson, James Whitney, Paul Sharits. In Light Moving in Time: Studies in the Visual Aesthetics of Avant-garde Film. University of California Press.

Weinel, J. Cunningham, S. Picking, R., \& Williams, L. (2014) Holophonor: On the Future Technology of Visual Music. In K. Curran (ed.), Recent Advances in Ambient Intelligence and Context Aware Computing. IGI Publishing.

Whitney, J. (1981) Digital Harmony: On the Complementarity of Music and Visual Art. McGrawHill Inc. 